




\title{
Estudo exploratório sobre sazonalidade e dependência turística em locais receptores: reflexões sobre Santa Catarina e as relações com o fluxo turístico da Argentina
}

Primary study on seasonality and dependence on inbound tourist locals: Reflections on Santa Catarina and relations with the flow of tourists from Argentina

\author{
Lisandro Fin Nishi ${ }^{1}$ \\ Giancarlo Moser²
}

1 Professor do Departamento de Ciências Econômicas da Universidade do Estado de Santa Catarina. Economista, Mestre em Economia e Coordenador do Projeto de Extensão de Análise da Conjuntura Econômica Catarinense da UDESC/Esag.

2 Professor do Departamento de Ciências Econômicas da Universidade do Estado de Santa Catarina. Historiador, Mestre em Turismo e Doutor em Gestão do Ensino Superior e Pós Doutor pela FGV. Também é Doutorando em Turismo na UNIVALI. 


\title{
Resumo
}

O turismo, pelas suas características, é uma atividade econômica particularmente atrelada às economias externas. Embora atraia divisas e, quando bem planejado, gera emprego e renda, esta relação de dependência enseja cautela. Este perigo aumenta ainda mais quando as regiões emissoras de turistas para a região são poucas, como é o caso de Santa Catarina. Este artigo mostra que o turismo catarinense é altamente dependente de seu país vizinho, a Argentina, fato que pode prejudicar sua economia. Sabe-se que o turismo na região é sazonal, com maior entrada de turistas nos meses de janeiro e fevereiro, período chamado de alta temporada, em que a entrada de turistas proveniente da Argentina representa a maioria dos turistas estrangeiros no estado. Ainda que seja inerente a dependência externa em se tratando de turismo, o que se pretende mostrar, através de revisão bibliográfica, é que no caso específico de Santa Catarina esta dependência é pode causar efeitos danosos. Conclui-se que Santa Catarina necessita diversificar as regiões emissoras de turistas, com objetivo de diminuir tal dependência e fortalecer seu desenvolvimento econômico.

Palavras-chave: Turismo em Santa Catarina; Dependência Externa; Argentina.

\begin{abstract}
Tourism, by its characteristics, is an economic activity particularly tied to external economies. Although attract foreign and, when well planned, generates jobs and income, this dependent relationship entails caution. This danger increases even more when the regions stations of tourists to the region are few, as in the case of Santa Catarina. This article shows that Santa Catarina tourism is highly dependent on its neighbor, Argentina, which could hurt its economy. It is known that tourism in the region is seasonal, with higher input tourists in January and February period called the high season, where the input from Argentina tourists represents the majority of foreign tourists in the state. Although it is inherent external dependency when it comes to tourism, which is intended to show, through literature review, it is that in the specific case of Santa Catarina is this dependence can cause harmful effects. The conclusion is that Santa Catarina need to diversify the regions stations of tourists, aiming to reduce such dependence and strengthen economic development.
\end{abstract}

Keywords: Tourism in Santa Catarina; External dependence ; Tourists from Argentina. 


\section{INTRODUÇÃO}

Para Lins $(2008)^{3}$, "O desenvolvimento do turismo é um dos traços marcantes do século XX". Porém, na conceituação do turismo, há que se diferenciar o "veIho turismo", aquele sintetizado pelo binômio "sol e mar", do novo turismo, mais abrangente e complexo, donde não se pode reduzir o turismo a um fetiche, voltado simplesmente para o lazer. Ainda, segundo Lins (2008), há um "perfil pós-moderno no realce do caráter plural das experiências turísticas, especialmente nos seus significados e motivações." Segundo Martins e Sicsú (2005), "as atividades turísticas envolvem diversos tipos de empresas que atuam em hospedagem, alimentação, transporte, organização, entretenimento, ensino, gestão pública, e outros", evidenciando a complexidade do tema atualmente.

Se houver cooperação entre as empresas que participam do turismo, pode-se ter a configuração de um cluster, que é benéfica a todos na região, uma vez que, para Martins e Sicsú (2005)4, "criará uma marca para essa região, identificando-a como um local muito favorável para bons negócios na sua área de atuação". Porém, o desenvolvimento de uma região, seja ela baseada no turismo ou não, nas economias modernas, não pode prescindir do planejamento socioeconômico e ambiental. Batista Filho (2003) afirma categoricamente que "o planejamento governamental deve estar vinculado à execução de ações para a viabilização do turismo como atividade produtiva, capaz de gerar empregos e promover o desenvolvimento economicamente viável, ecologicamente correto e socialmente justo".

Por este motivo, sendo Santa Catarina uma região com ímpar potencial turístico, o planejamento sustentado do turismo na região torna-se imprescindível. Ainda, conforme Batista Filho (2003), não basta que a região seja atraente em termos de fatores primários, tais como os recursos naturais, infraestrutura e recursos humanos, posto que "um crescimento desordenado, via de regra, apresenta-se como fonte de problemas deturpadores dos benefícios sociais decorrentes de qualquer atividade econômica". Seu pensamento sobre a necessidade de planejamento pode ser traduzido na sua frase: "O seu sucesso torna-se improvável a partir de um desenvolvimento espontâneo".

Avila, Moreno e Gândara (2004)5 afirmam que esta atividade - o turismo -, “(...) pode não ser tão benéfica para as sociedades receptoras como possa parecer". A título exemplificativo, a capital catarinense, Florianópolis, "é uma cidade na qual o turismo surgiu com salvação econômica e recentemente começam a aparecer os

3 Disponível em: http://www.apec.unesc.net/II\%20EEC/sessoes_tematicas/Regional/Artigo7.pdf

4 Disponível em: http://www.simpep.feb.unesp.br/anais/anais_12/anais_12.php

5 Disponível em: www.uesc.br/dcec/marco1.doc 
problemas mais graves ocasionados por ele", resultado de "(...) uma visível falta de planejamento". Além disso, Santa Catarina apresenta pouca diversidade de emissores de turistas, dentro os quais a maioria dos estrangeiros são provenientes da $\mathrm{Ar}$ gentina, fato que revela uma fragilidade do setor, posto que tal dependência deixa a região particularmente vulnerável das condições econômicas de seu país vizinho.

$\mathrm{O}$ presente estudo justifica-se, ainda, devido à conjuntura econômica recente. $\mathrm{O}$ trabalho de Meurer (2008) sobre a relação turística entre Brasil e Argentina mostrou que há correlação entre a taxa de câmbio real, a receita gerada pelos argentinos em Santa Catarina e o número de turistas argentinos em Santa Catarina. Em um determinado momento em que a economia argentina encontra-se fragilizada, uma deterioração das condições econômicas no país vizinho, somada de uma tendência desfavorável da taxa real de câmbio entre os dois países, pode ser extremamente prejudicial à economia catarinense.

Este artigo aponta que o turismo catarinense é altamente dependente do turista argentino, o que torna sua economia também dependente da economia do país vizinho, pois entende-se que Santa Catarina é um dos estados federativos com uma das melhores capacidades de recepção e de atrativos para os turistas nacionais ou estrangeiros - sejam provenientes do Cone Sul ou de países mais distantes -, e o turismo, nesse estado federativo, representa em torno de 12,5\% do PIB do Estado. ${ }^{6}$

É inegável que a atividade turística é um poderoso gerador de receitas no mundo inteiro e a sua capilaridade e as suas distintas modalidades (praias, turismo rural, turismo de aventura, turismo de negócios, feiras, shows entre outros) criam diversos postos de trabalho, tanto através do emprego direto na indústria do turismo ou indiretamente em setores como varejo e transporte. Quando os turistas gastam em bens e serviços ocorre o que é conhecido como o "efeito multiplicador", criando mais empregos diretos e indiretos nos locais visitados.

A indústria do turismo também oferece oportunidades para as empresas de pequena escala, o que é especialmente importante em comunidades rurais, e gera receitas fiscais adicionais, como os impostos em aeroportos e hotéis e que podem ser revertidos nos serviços públicos das comunidades receptoras.

\subsection{Objetivos}

Objetiva-se com este estudo demonstrar a necessidade de alguma redução da dependência econômica do turismo de Santa Catarina perante a Argentina, bem como

6 Conforme dados do Floripa Convention \& Visitors Bureau, em 2014. 
apresentar que: a) atualmente existe uma divisão internacional do trabalho, onde alguns países se especializaram economicamente no Turismo; b) Apresentar estatísticas do turismo em Santa Catarina, no Brasil e no Mundo; c) Mostrar que Santa Catarina recebe em sua maioria turistas provenientes da Argentina e esclarecer que a economia do turismo catarinense é, em grande parte, atrelada à economia argentina.

\section{DIVISÃO DO TRABALHO E DEPENDÊNCIA EXTERNA}

Segundo Brasseul (2010), no Paleolítico, já se encontrava uma divisão do trabalho: homens na caça, mulheres na colheita. Porém, segundo ele, "as grandes civilizações da Antiguidade surgiram depois da Revolução Neolítica que, a cerca de 10000 anos, assistiu ao nascimento e à extensão da agricultura até cerca de 3500 antes da nossa era". Nessa época, na região onde situa-se atualmente o Iraque, as condições geoclimáticas foram propícias para o surgimento das cidades, e as comunidades sedentarizaram-se. Como consequência, a existência de um excedente da produção levou a uma divisão do trabalho mais avançada: surgem as ocupações como artesãos, atividades de serviços como sacerdotes e administradores. Em meados do IV milênio a.C, surgem os grandes centros urbanos, a escrita e uma organização social mais complexa.

No desenvolvimento desta maior complexidade, povos passam a efetuar intercâmbios comerciais: o Egito, por exemplo, importa madeira a partir da costa libanesa. Os Fenícios inventam o comércio marítimo e vivem mais das trocas do que da produção, comercializando inclusive com tribos desconhecidas: vendem tecidos, perfume e joias em troca de matérias-primas; buscam ferro, prata e chumbo da Espanha, bem como ouro, marfim e madeira da África. As trocas entre povos foram tornando-se mais constantes, porque havia falta de matérias-primas, e a necessidade de importar e exportar acarretou no surgimento de entrepostos comerciais, das casas de comércio, e da moeda (BRASSEUL, 2010).

Sem sobra de dúvida, antes, e ainda hoje, este intercâmbio comercial entre povos tem como objetivo beneficiar ambas as partes envolvidas na transação. Porém, nos dias atuais, a questão tem se tornado cada vez mais complexa, chegando ao ponto em que se pode argumentar que nem sempre, em uma relação comercial, ambos os lados são beneficiados.

Neste contexto, o mesmo raciocínio vale para o turismo, uma vez que o turismo envolve diversos povos, que vão muito além de uma simples viagem de lazer: há também intercâmbio de culturas, de conhecimentos. Alguns países especializaram-se no turismo, por exemplo. Desta forma, em havendo uma divisão do trabalho (internacional), suas economias tornam-se dependentes desta atividade. 
Mannheim (1962) afirmou que quanto mais industrializada é uma sociedade, mais avançada sua divisão do trabalho e sua organização, e maior será o número de esferas de atividade humana funcionalmente racionais e, portanto, também previsíveis. Cabe lembrar ainda que garantir a previsibilidade de comportamentos e situações sempre foi uma aspiração dos administradores e até mesmo uma necessidade da organização formal.

Então, enquanto nas sociedades antigas, apenas ocasionalmente e em esferas limitadas, o indivíduo agia de uma maneira funcionalmente racional, na sociedade contemporânea ele é obrigado a agir dessa forma em um número de dimensões da vida cada vez maior.

A modernização, na verdade, implica absolutamente na racionalidade objetiva funcional, isto é, na organização das atividades humanas para finalidades estritamente objetivas. Não promove, nas mesmas proporções, a racionalidade substantiva, ou a capacidade de agir com inteligência plena numa determinada situação, com base na percepção própria da inter-relação e interdependência dos acontecimentos.

O economista clássico David Ricardo, ao publicar a obra "Princípios de Economia Política e Tributação", em 1817, disse que os países deveriam se especializar na produção de certos bens, onde possuíam vantagens comparativas. Muito embora o célebre economista escocês Adam Smith já houvesse mostrado as vantagens da especialização na produção, em sua obra "A Riqueza das Nações", de 1776, o livro de Ricardo foi extremamente importante na medida em que serve como base teórica para justificar a divisão internacional na produção de bens, enquanto o exemplo da Smith aplicava-se à especialização produtiva em âmbito microeconômico. Smith inicia sua obra escrevendo sobre a divisão do trabalho:

"O maior aprimoramento das forças produtivas do trabalho, e a maior parte da habilidade, destreza e bom senso com os quais o trabalho é em toda parte dirigido ou executado, parecem ter sido resultados da divisão do trabalho". Em seu exemplo, ao descrever uma fábrica de alfinetes, afirmava que um operário não treinado para a atividade (fabricar alfinetes), dificilmente conseguiria fabricar vinte. Porém, no momento em que a fabricação de alfinetes passa a ser dividida em várias atividades "Um operário desenrola o arame, um outro o endireita, um terceiro o corta, um quarto faz as pontas, um quinto o afia nas pontas...", descreve que em uma pequena manufatura em que dez operários executavam aproximadamente duas ou três operações distintas, no que produziam mais de 48000 alfinetes por dia. Em uma economia contemporânea, não há dúvidas de que no âmbito microeconômico a divisão do trabalho incrementa a produtividade. Porém, neste trabalho se levanta a 
discussão em torno desta divisão no âmbito macroeconômico, e mais precisamente ainda, em termos de turismo. Para tal, vejamos um trecho do livro de Ricardo:

Num sistema comercial perfeitamente livre, cada país naturalmente dedica seu capital e seu trabalho à atividade que lhe seja mais benéfica. Essa busca de vantagem individual está admiravelmente associada ao bem universal do conjunto dos países. Estimulando a dedicação ao trabalho, recompensando a engenhosidade e propiciando o uso mais eficaz das potencialidades proporcionadas pela natureza, distribui-se o trabalho de modo mais eficiente e mais econômico, enquanto, pelo aumento geral do volume de produtos, difunde-se o benefício de modo geral e une-se a sociedade universal de todas as nações do mundo civilizado por laços comuns de interesse e de intercâmbio. Este é o princípio que determina que o vinho seja produzido na França e em Portugal, que o trigo seja cultivado na América e na Polônia, e que as ferramentas e outros bens sejam manufaturados na Inglaterra.

Nesta citação, claramente se percebe a defesa de Ricardo em relação ao intercâmbio comercial entre países, uma vez que a troca elevaria o bem-estar conjunto. Porém, a explicação de qual item cada país deveria se especializar está presente em seu livro, a partir de um exemplo:

A Inglaterra pode estar em tal situação que, necessitando do trabaIho de 100 homens por ano para fabricar tecidos, poderia, no entanto, precisar do trabalho de 120 durante o mesmo período, se tentasse produzir vinho. Portanto, a Inglaterra teria interesse em importar vinho, comprando-o mediante a exportação de tecidos.

Em Portugal, a produção de vinho pode requerer somente o trabalho de 80 homens por ano, enquanto a fabricação de tecido necessita do emprego de 90 homens durante o mesmo tempo. Será, portanto, vantajoso para Portugal exportar vinho em troca de tecidos. Essa troca poderia ocorrer mesmo que a mercadoria importada pelos portugueses fosse produzida em seu país com menor quantidade de trabalho que na Inglaterra. Embora Portugal pudesse fabricar tecidos com o trabalho de 90 homens, deveria ainda assim importá-los de um país onde fosse necessário o emprego de 100 homens, porque Ihe seria mais vantajoso aplicar seu capital na produção de vinho, pelo qual poderia obter mais tecido da Inglaterra do que se desviasse parte de seu capital do cultivo da uva para a manufatura daquele produto" (RICARDO, 1996, p.98)

Na história do Brasil, não há dúvidas de que por centenas de anos fomos grandes especialistas na produção de produtos minerais e agrícolas: Em Lacerda et al (2005, p.16) encontramos menção aos ciclos econômicos brasileiros do pau-brasil, borracha, cana-de-açúcar, cacau, café e do ouro. $O$ fato de o país ter, durante certo período de tempo, se especializado na produção destes bens é perfeitamente explicável segundo a ótica de Ricardo. 
Segundo Lacerda et al (2005, p.16), a produção açucareira foi o eixo da economia colonial no século XVI até quase o final do XVIII, uma vez que o açúcar era um produto nobre para exportação, com destaque no plano internacional. Já o ciclo do ouro ocorreu durante dois séculos de exploração (XVII e XVIII), acarretando movimentos migratórios em direção a Minas Gerais, e o desenvolvimento da agricultura e da pecuária, como atividades acessórias à produção mineradora. FURTADO (2006, p. 67) diz que "o último quartel do século XVIII veria a decadência da mineração do ouro no Brasil", ao passo em que nessa época "A Inglaterra já havia, sem embargo, entrado na Revolução Industrial". Assim, no século XVIII a agricultura volta a ser a principal atividade econômica brasileira.

Com facilidade pode-se perceber que o ciclo do ouro não foi favorável ao desenvolvimento econômico brasileiro, posto que desestimulava qualquer avanço fabril. O fato é que, durante a fase dos ciclos econômicos, nosso país teve dificuldades para desenvolver o mercado interno. A produção manufatureira não se desenvolveu, enquanto o país mantinha-se voltado para a exportação.

Por diversas razões, como vimos, o Brasil não foi capaz de adentrar o século XIX com uma ampla e dinâmica economia de mercado. Inserido desde o início na periferia do sistema capitalista, não pôde converter as imensas riquezas que tinha produzido durante três séculos de sua história em desenvolvimento econômico e social. Sua passagem de uma era para outra - de colônia para estado - nação - seria carimbada pela permanência do atraso estrutural vivido pelo maior país do continente sul-americano. Na primeira metade do século XIX, após o fim do período colonial, na época do renascimento agrícola, não se registravam alterações substantivas nessa estrutura brasileira arcaica. (LACERDA et. al, 2005, p.25)

Para Lacerda et al (2005, p. 49), a formação da indústria começou no Brasil somente no último quartel do século XIX, no momento em que as condições para tal encontravam-se presentes: com a abolição da escravatura, a mão de obra assalariada era suprida pela imigração em massa, e a deterioração das estruturas pré-capitalistas. Para Furtado (2006, p. 71), "É das tensões internas da economia cafeeira, em sua etapa de crise que surgirão os elementos de um sistema econômico autônomo, capaz de gerar o seu próprio impulso de crescimento, concluindo-se então definitivamente a etapa colonial da economia brasileira". A crise da economia cafeeira deveu-se a um encadeamento de fatores, em resumo: o excesso de oferta, estimulado inclusive por políticas de proteção ao produtor (desvalorizações da moeda doméstica, compra de excedentes de produção), e por fim a Grande Depressão de 1929, que restringiu o crédito do governo.

Com o início da industrialização brasileira, ainda que tardia (MELLO, 2009), o Bra- 
sil passa a modificar-se estruturalmente, fato que irá contribuir para reduzir sua dependência econômica externa. Até aqui, o que se viu foi um país essencialmente agrário, voltado para a exportação, especializado, "enquadrado" na divisão internacional do trabalho. Tal situação está claramente descrita a seguir.

A propagação desigual do progresso técnico (que é visto como a essência do desenvolvimento econômico) se traduz, portanto, na conformação de uma determinada estrutura da economia mundial, de uma certa divisão internacional do trabalho: de um lado, o centro, que compreende o conjunto das economias industrializadas, estruturas produtivas diversificadas e tecnicamente homogêneas; de outro, a periferia, integrada por economias exportadoras de produtos primários, alimentos e matérias-primas, aos países centrais, estruturas produtivas altamente especializadas e duais. (MELLO, 2009, p.16)

A raiz do problema, conforme explanação da CEPAL (1949), reside na baixa dinâmica dos setores primários, os quais não possuem o poder de estimular a atividade industrial. Soma-se a isso o fato de que as economias periféricas, enquanto exportadoras de produtos primários, dependerem do vigor da demanda externa.

Uma importante crítica a esta especialização produtiva, a esta divisão internacional do trabalho, é que o desenvolvimento entre os países centrais (industrializados) e periféricos passa a ser desigual: enquanto os países centrais incrementam sua produtividade, os países periféricos caracterizam-se por apresentar baixo dinamismo e progresso técnico, mecanismo que a CEPAL (1949) chamou atenção por levar a uma deterioração dos termos de troca. Batista Filho (2003), em raciocínio semeIhante, diz que "o desequilíbrio nas relações de troca de diversos bens e serviços entre países ricos e pobres, portanto, se repete com o produto turístico..." Szmrecsanyi e Coelho (2007) explicam como ocorre a deterioração dos termos de troca.

O ritmo de incorporação do progresso técnico e de aumento da produtividade seria significativamente maior nas economias industriais (centro) do que nas economias especializadas (periferia), o que levaria por si só a uma diferenciação secular da renda favorável às primeiras. Além disso, os preços de exportação dos produtos primários tenderiam a apresentar uma evolução desfavorável face aos dos bens manufaturados produzidos pelos países industrializados. Como resultado, haveria uma tendência à deterioração dos termos de troca que afetaria negativamente os países latino-americanos através da transferência dos ganhos de produtividade no setor primário-exportador para os países industrializados. (SZMRECSÁNYI e COELHO, 2007).

Deve-se ainda considerar outros fatores e que demonstram que existem alguns custos ocultos provenientes do turismo e que podem ter efeitos econômicos e sociais desfavoráveis sobre as comunidades receptivas. Muitas vezes, os países desen- 
volvidos são mais capazes de lucrar com o turismo do que os em desenvolvimento. Considerando-se que os países menos desenvolvidos têm a necessidade mais urgente de renda, emprego e aumento geral do nível de vida por meio do turismo, eles são menos capazes de obter esses benefícios em um curto espaço de tempo. Entre as razões para isso são a transferência em grande escala de receitas do turismo para fora do país de acolhimento e a exclusão de empresas e produtos locais.

A renda direta transferida para uma área é o montante das despesas do turista que permanece no local após os impostos, os lucros e os salários pagos fora da área. $\mathrm{Na}$ maioria dos pacotes turísticos com tudo incluído, cerca de $80 \%$ dos viajantes internacionais atuais, as despesas são com as companhias aéreas, hotéis e outras empresas internacionais - que muitas vezes têm a sua sede nos países de origem -, e não com empresas, serviços ou trabalhadores no local do turismo receptivo.

Da mesma forma, o comportamento do visitante pode ter um efeito nocivo sobre a qualidade de vida da comunidade de acolhimento. Podem ocorrer, por exemplo: congestionamentos, problemas com drogas e alcoolismo, prostituição e aumento dos níveis de criminalidade. $O$ turismo pode até mesmo infringir os direitos humanos, com os moradores locais sendo deslocados das suas áreas para abrir caminho para novos empreendimentos turísticos e a interação dos locais com os turistas também pode levar a uma erosão de culturas e valores tradicionais.

Sair desta situação, após tal diagnóstico, seria possível via industrialização, via independência econômica, estimulando o mercado interno, criando uma dinâmica interna, a qual não ocorria devido à estrutura econômica vigente, agroexportadora. Neste sentido, o planejamento econômico é imperativo para modificar as condições estruturais de uma economia. Entretanto, nosso objetivo, nesta seção, foi mostrar que a dependência externa, no passado brasileiro, pode ter sido responsável pelo atraso no desenvolvimento econômico brasileiro.

Em se tratando do turismo, por sua natureza dependente, o perigo está em atrelar o dinamismo econômico da região à do resto do mundo, perigo que se amplia quando poucos são os países emissores, como é o caso de Santa Catarina, conforme será mostrado no capítulo seguinte.

\section{TURISMO}

\subsection{Origens do Turismo}

Para Castelli (2006), o desenvolvimento do turismo nos dias atuais provém do ato de acolher e da hospitalidade, o que já era praticado nos primórdios da civi- 
lização humana. Enquanto eram nômades, necessitavam de cooperação na caça de grandes presas, e acabavam por dividir o produto da caça, nascendo assim, a hospitalidade à mesa. Essa cooperação, associada ao ato de comer junto geravam momentos de sociabilidade. Tais comportamentos sempre estiveram presentes nas diversas civilizações: na Grécia antiga, por volta de 450 a.C, ao receber um hóspede, dispensavam atenção sem reservas, uma vez que acreditavam poder estar recebendo, nesse hóspede, a própria divindade (Zeus) disfarçado de visitante.

Na China, no tempo da Dinastia Chou, o ato de comer junto "representava um momento importante para a prática da hospitalidade, da sociabilidade e da conviviabilidade." (CASTELLI, 2006, p. 46). Em se tratando da Civilização Romana (cujo apogeu se deu por volta de 100 d.C.), os romanos ofereciam a seus hóspedes toda a proteção, pois eram responsáveis por eles. Merecem destaque os banquetes, marcados por um luxo exuberante, um acontecimento marcante da vida social romana, e os meios de hospedagem; estes haviam de diversos tipos, para hospedar viajantes de diversas categorias: militares, funcionários, comerciantes e turistas. Enquanto no período Feudal a liberdade de locomoção ficou restrita, ainda assim surgiram meios de hospedagem de ordens religiosas para receber peregrinos, as quais contribuíram para a troca de ideias e aquisição de conhecimentos, o que perdurou durante o Cristianismo: a título exemplificativo, "A Regra de São Bento" trata de como receber hóspedes. (CASTELLI, 2006)

Na Idade Contemporânea (do século XVIII aos dias atuais), o ato de viajar é uma das atividades mais apreciadas. Mais do que acolher, receber, o turismo atualmente defronta-se com um caráter multifacetado. Para Swarbrooke e Horner (2002), "o turismo é definido como uma movimentação, de curto prazo, de pessoas para lugares algo distantes do local em que residem regularmente, com a finalidade de usufruir atividades prazerosas." Também incluem como turismo as viagens de negócios, o turismo educacional, o turismo hedonista, entre outros.

A história do Turismo é tratada por Lage e Milone (1998) como sendo desde os primeiros movimentos de viagens e representa um dos elementos componentes da vida econômica e social dos homens no decorrer de cada época e para cada civilização. Fazendo uma abordagem histórica, os autores demonstram que o turismo se desenvolveu diferentemente nas várias civilizações, mas sempre esteve atrelado a importantes componentes econômicos na sua evolução.

O turismo pode ser focalizado como um fenômeno que se refere ao movimento de pessoas dentro de seu próprio país (turismo doméstico) ou cruzando as fronteiras nacionais (turismo internacional). Este movimento revela elementos tais como 
interações e relacionamentos individuais e grupais, compreensão humana, sentimentos, percepções, motivações, pressões, satisfação, a noção de prazer, etc.

De acordo com Castelli (1992), a compreensão do fenômeno turístico atual deve necessariamente passar por uma análise sobre o significado das viagens no decorrer da história. Estas quase sempre foram movidas por interesses econômicos, políticos e militares. Viagens com estes mesmos objetivos continuam hoje a movimentar pessoas de uma região para outra.

No entanto, ao longo da história, paralelamente às viagens realizadas com os objetivos anteriormente mencionados, registram-se também aquelas movidas por outros interesses tais como: curiosidade, saúde, cultura, religião, descanso entre outros.

A viagem turística tornou-se, na era moderna, uma realidade econômica, social, cultural e política incontestável. $\mathrm{O}$ aparecimento, no séc. XX, das inúmeras organiza-

ções de turismo, decorre do surgimento e prática das viagens em grande escala. Tais viagens são uma consequência das necessidades geradas pela sociedade industrial.

A viagem é uma ação decorrente de todo um contexto dentro do qual está inserida a sociedade em um determinado momento da história. A viagem sempre foi um dos elementos componentes da vida econômica e social e, sobretudo do mundo dentro do qual está inserida. A cada tipo de civilização ou sociedade corresponde uma maneira de se viajar ou acolher o viajante.

\subsubsection{Conceitos de Turismo}

Os vários conceitos de turismo se perdem em uma infinidade de autores que presos à areia movediça da multiplicidade de aspectos que cercam a atividade turística o definem baseados, por sua vez, em outros autores, e um consenso entre os estudiosos está longe de ser avistado. Contudo, existe uma tendência em se considerar qualquer movimento de viagem para fora da área de habitação natural de um indivíduo, ou seja, sua casa, como uma viagem de turismo. É óbvio que esta definição não encerra em si todos os movimentos de um cidadão no sentido de deixar o seu lar cotidianamente, como por exemplo: ir ao trabalho, às compras, à cultos religiosos etc. Discute-se aqui as viagens motivadas por fatores lazer, ou compras, negócios e convenções em cidades diversas da de origem do indivíduo.

Uma das primeiras definições consistentes dada ao termo turismo foi estabelecida, possivelmente, pelo economista austríaco Herman Von Schullard em 1910 (apud LAGE e MILONE, 1998, p. 76), sendo "a soma das operações, principalmente de natureza econômica, que estão diretamente relacionadas com a entrada, perma- 
nência e deslocamento de estrangeiros para dentro e para fora de um país, cidade ou região". Este conceito contempla duas ideias básicas: de que o turismo se caracteriza por várias operações, principalmente, de natureza econômica e que está relacionado ao movimento de estrangeiros.

A Comissão Econômica da Liga das Nações (1937) definiu o turista para fins de estatísticas internacionais de viagens como: "qualquer pessoa que viaje por um período de 24 horas ou mais em um país que não seja o de sua residência". Por volta de 1942, os professores suíços Hunziker e Kraper (apud IGNARRA, 1998, p. 42) completaram conceituações anteriores sobre o turismo como "o complexo de relações e fenômenos relacionados com a permanência de estrangeiros em uma localidade, pressupondo-se que estes não exerçam uma atividade principal, permanente, ou temporária remunerada". Pela própria estrutura da atividade, pode-se definir o turismo como o conjunto de serviços que tem por objetivo o planejamento, a promoção e a execução de viagens, e os serviços de recepção, hospedagem e atendimento aos indivíduos e aos grupos, fora de suas residências habituais.

O turismo pode ser focalizado como um fenômeno que se refere ao movimento de pessoas dentro de seu próprio país (turismo doméstico) ou cruzando as fronteiras nacionais (turismo internacional). Este movimento revela elementos tais como interações e relacionamentos individuais e grupais, compreensão humana, sentimentos, percepções, motivações, pressões, satisfação, a noção de prazer, etc.

Alguns conceitos econômicos que influenciam o estudo do turismo como indústria são: bem econômico, utilidade, agentes econômicos, produto turístico, demanda e oferta turística. Conforme Lage e Milone (1998), tudo o que é raro e existe em menor quantidade do que a necessidade é um bem econômico. Assim, em virtude dessa carência, necessitam ser produzidos, tomando a forma de bens (materiais) ou de serviços (imateriais).

Produzir, no sentido econômico, diz respeito a criar utilidade ou aumentar a utilidade dos bens econômicos. Utilidade é então definida como a qualidade que possuem os bens econômicos de satisfazer as necessidades humanas. Ela é também considerada como o grau de satisfação que os consumidores atribuem aos bens e serviços. Como o consumidor não pode obter tudo o que deseja, é obrigado a fazer escolhas. Portanto, se preferir mais de um determinado bem e serviço, deve aceitar uma quantidade menor de outro. No entanto, em qualquer situação, o consumidor age racionalmente no sentido de obter a máxima satisfação de seus gastos.

Os principais agentes econômicos são os consumidores e as empresas. Sendo os primeiros responsáveis pelo consumo, e tendo como objetivo a maximização 
de suas satisfações, e os segundos responsáveis pela produção de bens e serviços procurando atingir lucros máximos.

No que tange ao turismo, alguns grupos que participam e afetam diretamente a produção e o consumo turístico de qualquer país são:

1. TURISTAS: grupo que procura experiências psíquicas e físicas tentando maximizar a utilidade (satisfação) de suas viagens;

2. EMPRESAS TURISTÍCAS: grupo que tem no turismo a oportunidade de aumentar seus lucros, através da oferta de vários tipos de bens e serviços demandados pelo mercado turístico;

3. PODER PÚBLICO: grupo que assume o turismo como fator econômico. Relaciona-se com as entradas de receita que os cidadãos obtêm desta indústria, com as divisas geradas pelo turismo internacional e com o aumento de arrecadação de impostos devido aos gastos turísticos na área e

4. COMUNIDADE RECEPTORA: grupo representado pelas pessoas nativas da região turística.

Cabe ressaltar que os objetivos e esforços combinados destes quatro grupos de agentes influenciam na determinação das atividades turísticas.

\subsection{Características do turismo brasileiro}

O Brasil não se encontra entre os primeiros no ranking dos principais destinos turísticos mundiais, conforme pode-se observar na Tabela 1. Curiosamente, apesar das grandes dimensões, da peculiar natureza e do clima ameno, condições efetivamente atrativas, ficamos atrás, em número de chegadas de turistas, de muitos países.

Esses dados revelam que o Brasil ainda não é um país totalmente bem preparado para receber o turista. Em véspera de Olimpíadas, apesar deste evento ajudar a elevar o fluxo de entrada de turistas e de divisas para o país no ano de sua realização, há também o perigo de não estarmos preparados para receber, de uma só vez, tantos turistas, o que pode ser bom apenas no curto prazo, com efeito contrário a longo prazo.

Esta assertiva pode ser tomada na comparação com o turismo que é desenvolvido em países como Itália, França e Espanha, antigas potências militares e colonialistas, que conseguiram estabilizar suas balanças de pagamento no após II guerra graças ao turismo, chegando ao ponto dessa atividade se constituir verdadeira indústria, com ministério próprio, legislação específica, que visa regulamentar os diversos aspectos sociais, econômicos, comerciais e culturais do Turismo, sempre objetivando 
melhor rendimento e maior expansão da indústria da paz.

O turismo no Brasil consolidou-se nas últimas décadas como setor importante na economia nacional e vem apresentando, até hoje, altas taxas de crescimento, e ao que tudo indica continuará em expansão. Além dos crescentes benefícios econômicos, o turismo traz benefícios sociais, ampliando o mercado de trabalho e melhorando a infra-estrutura de lazer. Por este último, são beneficiadas crescentes faixas da sociedade brasileira que participam do turismo, como também os moradores das regiões turísticas. Ao contrário da indústria, o produto turístico não vai ao consumidor, mas o consumidor vai ao produto, e este consiste de um conjunto de serviços cuja qualidade é altamente dependente de fatores externos, como da qualidade de infra-estrutura urbana e do meio ambiente.

Tabela 1: Turistas (milhões de chegadas)

\begin{tabular}{|l|c|}
\hline PAÍSES DE RESIDÊNCIA PERMANENTE & CHEGADAS \\
\hline Mundo & 982 \\
\hline França & 79,5 \\
\hline Estados Unidos & 62,3 \\
\hline China & 57,6 \\
\hline Espanha & 56,7 \\
\hline Itália & 46,1 \\
\hline Turquia & 29,3 \\
\hline Reino Unido & 29,2 \\
\hline Alemanha & 28,4 \\
\hline Malásia & 24,7 \\
\hline México & 23,4 \\
\hline Áustria & 23,0 \\
\hline Rússia & 22,7 \\
\hline Hong Kong (China) & 22,3 \\
\hline Ucrânia & 21,4 \\
\hline Tailândia & 19,1 \\
\hline Brasil & 5,4 \\
\hline Outros & 430,9 \\
\hline Fonte: Ministério do Turismo. Estatísticas Básicas do Turismo, 2011 \\
\hline
\end{tabular}

No ano de 2011, por exemplo, o Brasil recebeu apenas 5,4 milhões de chegadas do total de 982 milhões do mundo, com uma taxa de crescimento médio, de 2000 a 2011, de apenas $0,15 \%$ ao ano. Tal crescimento mostra que estamos ficando para trás relativamente ao mundo, o que pode ser visto no gráfico 2 , que mostra o número de chegadas no mundo e no Brasil, em índice com base no ano 2000. 


\section{Gráfico 1: Chegadas de Turistas Internacionais no Mundo (base $2000=1$ )}

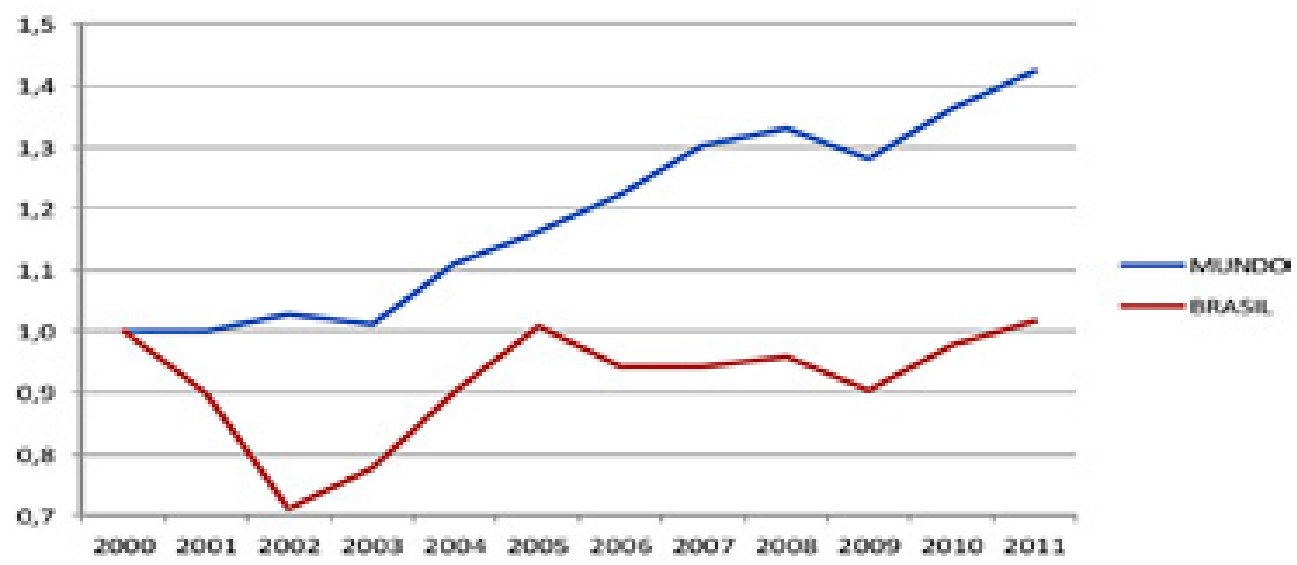

Fonte: dos autores

Através deste gráfico facilmente se visualiza que há 11 anos nosso país encontra-se praticamente estagnado em termos de atratividade ao turista internacional, enquanto que o mundo cresceu, neste período, em média 3,85\% ao ano. Com crescimento abaixo da média mundial, o Brasil, que detinha $0,77 \%$ da participação percentual de turistas no mundo, no ano 2000, em 2011 deteve 0,55\%.

Ressalta-se que, além da dificuldade para atrair o turista estrangeiro, o brasileiro gosta de viajar, o que se reflete na Balança de Serviços, cuja conta de turismo costuma ser deficitária, déficit este que tem crescido nos últimos anos, conforme dados da Tabela 2.

Tabela 2: Conta viagens internacionais (us\$ milhões)

\begin{tabular}{|l|c|c|c|c|c|}
\hline \multicolumn{1}{|c|}{ DISCRIMINAÇÃO } & 2008 & 2009 & 2010 & 2011 & 2012 \\
\hline VIAGENS INTERNACIONAIS & -5177 & -5594 & -10718 & -14709 & -15588 \\
\hline RECEITA & 5785 & 5305 & 5702 & 6555 & 6645 \\
\hline Fins educacionais, culturais ou esportivos & 11 & 9 & 48 & 63 & 64 \\
\hline Funcionários de governo & 26 & 22 & 39 & 22 & 42 \\
\hline Negócios & 59 & 47 & 51 & 55 & 46 \\
\hline Por motivos de saúde & 36 & 35 & 42 & 48 & 43 \\
\hline Turismo & 2855 & 2016 & 1207 & 1425 & 1449 \\
\hline Cartões de crédito & 2799 & 3175 & 4316 & 4943 & 5002 \\
\hline DESPESA & -10962 & -10898 & -16420 & -21264 & -22233 \\
\hline Fins educacionais, culturais ou esportivos & -42 & -49 & -297 & -348 & -377 \\
\hline Funcionários de governo & -37 & -55 & -69 & -37 & -78 \\
\hline Negócios & -471 & -320 & -444 & -465 & -400 \\
\hline Por motivos de saúde & -17 & -18 & -23 & -25 & -32 \\
\hline Turismo & -3902 & -3870 & -5421 & -7720 & -9031 \\
\hline Cartões de crédito & -6493 & -6587 & -10166 & -12670 & -12314 \\
\hline
\end{tabular}

Fonte: Banco Central do Brasil. Série Temporal do Balanço de Pagamentos. 
Vale a pena observar que na conta de viagens internacionais, as despesas referentes a "negócios" têm reduzido seu déficit, indicando que nosso país tem logrado êxito ao menos a atrair pessoas de negócios, o que pode significar um ambiente empresarial mais próspero. Também é importante ressaltar que há iniciativas para fomentar o turismo no Brasil: a Tabela 3 mostra que o desembolso dos Bancos Federais cresceu significativamente de 2003 a 2011, e recentemente, em 2012, o Banco Regional de Desenvolvimento do Extremo Sul (BRDE) lançou programa para fomentar o turismo nos estados que compõem o Conselho de Desenvolvimento e Integração do Sul, o qual inclui Santa Catarina.

Tabela 3: Desembolso para Financiamento do Turismo

\begin{tabular}{|l|c|c|}
\hline & \multicolumn{2}{|c|}{ DESEMBOLSO (R\$ MIL) } \\
\hline BANCO & $\mathbf{2 0 0 3}$ & $\mathbf{2 0 1 1}$ \\
\hline BANCO DO BRASIL & 738.504 & 2.924 .648 \\
\hline CAIXA ECONÔMICA FEDERAL & 244.399 & 4.281 .118 \\
\hline BNDES & 57.259 & 997.415 \\
\hline BANCO DO NORDESTE & 48.416 & 288.455 \\
\hline BANCO DA AMAZÔNIA & 5.746 & 117.629 \\
\hline
\end{tabular}

Fonte: Ministério do Turismo. Estatísticas Básicas do Turismo, 2011

\subsection{Características do turismo em Santa Catarina}

Nesta seção específica, mostraremos dados sobre o turismo em diversas regiões de Santa Catarina, a saber: Balneário Camboriú, Balneário Piçarras, Garopaba, Joinville, Laguna, São Bento do Sul, Treze Tílias e Urubici, pois são as regiões que foram objeto de Pesquisa da Santur em 2013, excluindo-se Piratuba, pois não apresentou dados para o mês de janeiro de 2013. Para Florianópolis a pesquisa utilizada foi do ano de 2012, uma vez que não havia pesquisa publicada para o ano de 2013, da capital catarinense. Inicialmente, serão mostrados dados consolidados de Santa Catarina.

Pesquisa da Santur (2013) mostra que os estrangeiros representaram 6\% dos turistas em Santa Catarina no ano de 2013, considerando o período da alta estação (janeiro e fevereiro). Embora o percentual possa parecer pequeno, a receita gerada pelos estrangeiros no mesmo período representou $11 \%$ do total, uma vez que o turista estrangeiro gasta em média mais em relação ao brasileiro.

O que é notório é que dos turistas estrangeiros que adentram o Estado de Santa Catarina, os argentinos são a maioria absoluta. Tais números mostram que, em termos de turistas estrangeiros, há uma básica dependência do turista argentino. O gráfico a 
seguir mostra claramente a liderança, como país emissor de turistas para Santa Catarina, da Argentina.

\section{Gráfico 2: Participação dos países emissores de turistas para Santa Catarina}

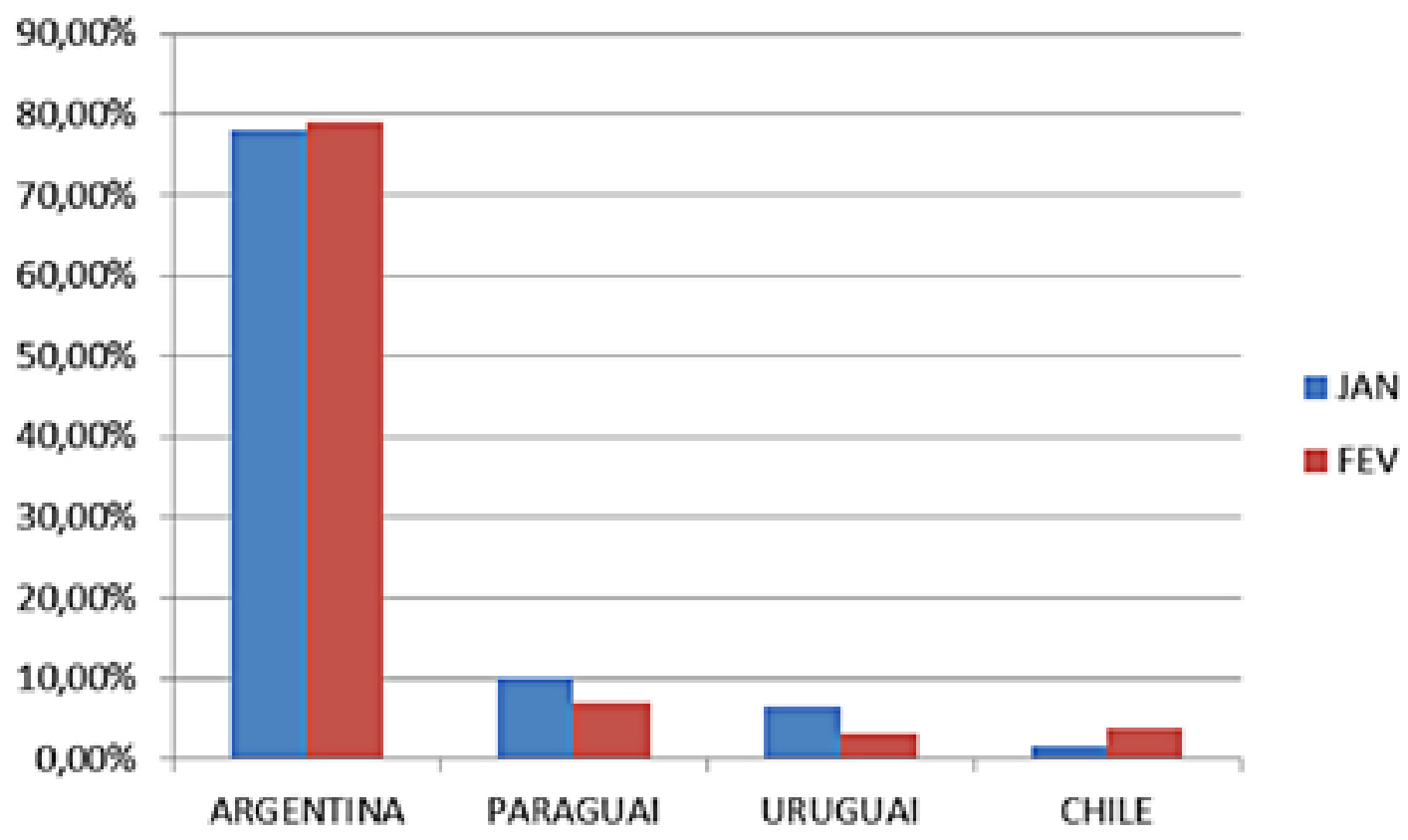

Fonte: Santur (2013)

A importância do turista estrangeiro é percebida tanto pela permanência média quanto pelo gasto médio, conforme é possível ver nas tabelas que seguem.

Tabela 4: Permanência média em todos os meios de hospedagem

\begin{tabular}{|l|c|c|}
\hline & Jan 2013 & Fev 2013 \\
\hline Nacionais & 8,00 dias & 6,56 dias \\
\hline Internacionais & 11,34 dias & 10,60 dias \\
\hline Fonte: Santur (2013)
\end{tabular}

Nos dois primeiros meses de 2013, o turista estrangeiro permaneceu em média $51 \%$ mais tempo que o turista brasileiro, e seu gasto médio superou o gasto do turista brasileiro em $28 \%$.

Tabela 5: Gasto médio diário estimado por turista

\begin{tabular}{|l|c|c|}
\hline & Jan 2013 & Fev 2013 \\
\hline Nacionais & $\mathrm{R} \$ 93,63$ & $\mathrm{R} \$ 95,57$ \\
\hline Internacionais & $\mathrm{R} \$ 112,56$ & $\mathrm{R} \$ 128,91$ \\
\hline Fonte: Santur (2013)
\end{tabular}


Tais dados inicialmente evidenciam inequivocadamente a influência do turista estrangeiro para a economia catarinense. Ao consideramos que os argentinos são a grande maioria neste contexto, uma preocupação torna-se iminente: uma parcela significativa do turismo em Santa Catarina encontra-se à mercê da economia argentina, em uma intima relação de dependência externa, pois conforme Theis e Jacomossi (2008), "Algumas cidades hospedam apenas um cluster que as tornam vulneráveis às intempéries econômicas".

Para Martins e Sicsú (2000), há um cluster turístico quando há a cooperação entre diversas empresas do mesmo ramo, indicando que no setor do turismo tal cooperação costuma ser fraca. Theis e Jacomossi (2008) enfatizam a importância dos clusters, ao identificarem que os municípios catarinenses de maior PIB apresentavam não somente a existência, mas também diversidade de clusters. Porém, Avila, Moreno e Gândara (2004) ao construírem uma matriz de avaliação estratégica para integração do lazer ativo à atividade turística em Florianópolis, identificaram como ameaças as "Incertezas econômicas no Brasil e nos países que compõem o MERCOSUL", e a "Pouca diversidade de emissores", fatos que conjuntamente vem a reforçar a importância do presente estudo. No quesito "pouca diversidade de emissores", comentam acerca da necessidade de avaliar a busca de novos mercados emissores, de forma a diminuir a dependência dos mercados tradicionais, dentre os quais citam: a Argentina, em especial, e os "fortes polos emissores", que são os estados de São Paulo, Rio Grande do Sul e Paraná. Por fim, o "Inadequado planejamento turístico" é também considerado uma ameaça presente.

A seguir, mostraremos dados a respeito da entrada de turistas argentinos para diversas regiões de Santa Catarina, objetivando evidenciar a liderança da argentina como país emissor de turistas estrangeiros para Santa Catarina.

Tabela 6: Percentual de argentinos entre os estrangeiros

\begin{tabular}{|c|c|}
\hline REGIÃO & ARGENTINOS (\% EM JAN/2013) \\
\hline Balneário Camboriú & 76,69 \\
\hline Garopaba & 87,09 \\
\hline Joinville & 55,55 \\
\hline Laguna & 50,00 \\
\hline
\end{tabular}

Fonte: Santur (2013)

Com base na Tabela 3 percebe-se que o percentual de argentinos é grande nas cidades do litoral catarinense, com destaque para as cidades de Balneário Camboriú, 
Garopaba e Florianópolis, onde em 2012, no mês de fevereiro (não há dados para janeiro de 2012), o percentual de argentinos entre os estrangeiros foi de $74,16 \%$.

Vale a pena destacar qual veículo de propaganda que influenciou na viagem, uma vez que esta informação é de grande valia para o planejamento de futuras ações de publicidade. Os dados da tabela referem-se ao mês de janeiro de 2013.

Facilmente pode-se observar que somente estes dois veículos - amigos/parentes ou internet - de propaganda somam quase $100 \%$. Em todas as cidades, a liderança está no veículo "amigos/parentes", mostrando que o turista leva em consideração principalmente os comentários de pessoas próximas, que provavelmente já estiveram no local. Isso mostra o quanto é importante que o turista leve consigo boas lembranças, pois além de retornar, pode ainda indicar o lugar e trazer consigo mais pessoas.

Tabela 7: Veículo de propaganda que influenciou na viagem

\begin{tabular}{|l|c|c|}
\hline CIDADE & AMIGOS / PARENTES & INTERNET \\
\hline Balneário Camboriú & $65,63 \%$ & $21,04 \%$ \\
\hline Balneário Piçarras & $78,25 \%$ & $12,99 \%$ \\
\hline Garopaba & $75,44 \%$ & $20,12 \%$ \\
\hline Joinville & $70,98 \%$ & $18,97 \%$ \\
\hline Laguna & $73,56 \%$ & $21,84 \%$ \\
\hline São Bento do Sul & $39,28 \%$ & $29,76 \%$ \\
\hline Treze Tílias & $50 \%$ & $39,58 \%$ \\
\hline Urubici & $60,56 \%$ & $33,80 \%$ \\
\hline
\end{tabular}

Fonte: Santur (2013)

Em segundo lugar vem a internet, evidenciando a necessidade de o setor turístico preparar-se para as novas tecnologias, não somente para a rapidez e confiabilidade na transmissão de dados, bem como saber atrair o turista com base na publicidade via internet, ou seja, ser profissional na área digital. Outra informação relevante diz respeito à taxa de ocupação da rede hoteleira nos meses de janeiro e fevereiro. 
Tabela 8: Taxa de ocupação da rede hoteleira (\%)

\begin{tabular}{|l|c|c|}
\hline CIDADE & JAN & FEV \\
\hline Balneário Camboriú & 84,00 & 78,00 \\
\hline Balneário Piçarras & 74,37 & 48,20 \\
\hline Garopaba & 74,23 & 63,40 \\
\hline Joinville & 45,73 & 50,27 \\
\hline Laguna & 68,86 & 65,27 \\
\hline São Bento do Sul & 45,34 & 48,56 \\
\hline Treze Tílias & 46,68 & 40,51 \\
\hline Urubici & 74,17 & 35,33 \\
\hline
\end{tabular}

Fonte: Santur (2013)

Os dados da taxa de ocupação da rede hoteleira revelam que nas cidades litorâneas a taxa de ocupação é maior relativamente à das cidades interioranas, mostrando que o turista busca principalmente as belezas naturais das praias catarinenses. Porém, a ocupação cai no mês de fevereiro, e ainda mais nos meses de baixa temporada. Em cidades como São Bento do Sul e Treze Tílias, por exemplo, a taxa de ocupação não chega a 50\%. Esses dados mostram que há necessidade de se levantar maneiras de atrair turistas fora do período da alta temporada. É inegável que fora do período de férias há uma dificuldade para viajar. Porém, com planejamento, também é possível que existam várias possibilidades de se gerar infraestrutura de Santa Catarina para receber turistas, cadastradas no Ministério do Turismo, posicionando o estado relativamente aos demais estados brasileiros (27 no total). 
Tabela 9: Infraestrutura turística

\begin{tabular}{|l|l|l|}
\hline ANO DE 2011 & SANTA CATARINA & POSIÇÃO \\
\hline Agências de turismo & 657 & $6^{\circ}$ \\
\hline Meios de hospedagem & 257 & $9^{\circ}$ \\
\hline Acampamentos turísticos & 1 & $7^{\circ}$ \\
\hline Restaurantes, bares e similares & 286 & $2^{\circ}$ \\
\hline Parques temáticos & 2 & $9^{\circ}$ \\
\hline Transportadoras turísticas & 260 & $6^{\circ}$ \\
\hline Locadoras de veículos & 6 & $13^{\circ}$ \\
\hline Organizadoras de eventos & 69 & $6^{\circ}$ \\
\hline Prestadoras de serviços $p /$ eventos & 27 & $5^{\circ}$ \\
\hline Guias de turismo & 130 & $14^{\circ}$ \\
\hline
\end{tabular}

Fonte: Ministério do Turismo. Estatísticas Básicas do Turismo, 2011

Esta tabela deixa claro que Santa Catarina, comparativamente aos demais estados do Brasil, possui uma das melhores infraestruturas para receber o turista, o que não se confunde com uma ótima infraestrutura.

\section{CONSIDERAÇÕES FINAIS}

A diversificação em uma economia é um sinal de saúde, no entanto, se um país ou região se torna dependente para sua sobrevivência econômica somente de um setor, esta comunidade pode gerar uma grande pressão sobre esta indústria, bem como sobre as pessoas envolvidas para um bom desempenho. Muitos países, especialmente os países em desenvolvimento com pouca capacidade para explorar outros recursos, abraçaram o turismo como uma maneira de impulsionar a economia.

A ascensão da atividade turística verificada nas últimas décadas e as excelentes perspectivas para o contínuo crescimento da mesma para este início do século XXI elevam as possibilidades de inserção de vários países e localidades nesta atividade altamente rentável e que, segundo a OMT (2011), já movimento US\$ 4,5 trilhões ao redor do planeta, colocando-a como uma das principais atividades econômicas de vários países.

Enquanto nações como a França atraem quase 70 milhões de turistas ao ano (OMT 2012), o Brasil, apesar de um intenso fluxo interno de turistas, representado principalmente pelo turismo doméstico, se coloca em uma posição modesta em relação ao mercado mundial, com um fluxo interno de, aproximadamente, $50 \mathrm{mi}$ - 
Ihões de turistas e com um número quase que inexpressivo no Turismo Receptivo mundial, recebendo 4,5 milhões de turistas, sendo que a maioria expressiva deste contingente é de turistas provenientes do Cone Sul, principalmente da Argentina, Paraguai, Uruguai e Chile. (EMBRATUR, 2013).

O excesso de confiança no turismo, especialmente o turismo de massa, traz riscos significativos para as economias dependentes do turismo, se não houver um planejamento consciente e sustentado, pois uma turbulência econômica no país destino e os impactos dos desastres naturais, como tempestades e ciclones tropicais, bem como mudanças nos padrões de turismo, podem ter um efeito devastador sobre o setor do turismo local.

Desta forma, vimos que o turismo é uma atividade econômica intrinsicamente atrelada às economias externas. Embora atraia divisas e, quando bem planejado, gere emprego e renda, uma economia baseada no turismo deixa a região à mercê das economias externas. Este perigo aumenta ainda mais quando as regiões emissoras de turistas para a região são poucas, como é o caso de Santa Catarina. A dependência externa em se tratando de turismo é fator inerente no desenvolvimento da atividade; porém, o que foi mostrado é que no caso específico de Santa Catarina, esta dependência gera riscos maiores no seu desenvolvimento, pois a entrada de turistas proveniente da Argentina representa a maioria dos turistas estrangeiros que adentram o estado. A fim de minimizar esta dependência, conclui-se que, por uma intensa política de planejamento público e privado, com ações distintas, tanto de marketing como de atrativos diferenciados, é necessário diversificar as regiões emissoras de turistas para Santa Catarina.

\section{REFERÊNCIAS BIBLIOGRÁFICAS}

AVILA, Marco Aurelio; MORENO, José Hernandez; GÂNDARA, José Manoel Gonçalves. O Lazer Ativo Como Fator de Atração Turística na Cidade de Florianópolis. Revista Turismo \& Desenvolvimento. V3, N1, 2004. Disponível em: www.uesc.br/dcec/ marco1.doc. Acesso em: 29 de novembro de 2015.

àBATISTA FILHO, Ernesto Luiz. Aspectos de planejamento, gestão e competitividade para o turismo sustentável no Brasil. Cadernos de Economia. Chapecó: Argos. Ano 7, n.12, 2003

CASTELLI, Geraldo. Hospitalidade. Na Perspectiva da Gastronomia e da Hotelaria. São Paulo: Saraiva, 2006.

Geraldo. Administração hoteleira. 5a ed. Caxias do Sul: EDUCS, 1992 
àCEPAL: Economic Survey of Latin America - 1949. Disponível em: <http:// www.seade.gov.br/produtos/bibliotecadigital/view/singlepage/index. php?pubcod=10011659\&parte $=1>$ Acesso em 21/05/2013

FURTADO, Celso. Formação Econômica do Brasil. São Paulo: Cia das Letras, 2006

IGNARRA, Luiz Renato. Fundamentos do turismo. São Paulo: Pioneira, 1998.

LAGE, B.; MILONE, P.. Economia do Turismo. Campinas: Papirus, 1998.

LACERDA, Antônio Corrêa de. et al. Economia Brasileira. São Paulo: Saraiva, 2005.

LINS, Hoyedo Nunes. Estilização do Turismo: Ensaio com Foco na Serra Catarinense. Anais do II Encontro de Economia Catarinense, 2008. Disponível em: http://www. apec.unesc.net/II\%20EEC/sessoes_tematicas/Regional/Artigo7.pdf. Acesso em: 29 de novembro de 2015.

MANNHEIM, Karl. O Homem e a sociedade: estudos sobre a estrutura social moderna. Rio de Janeiro: Zahar, 1962.

MARTINS, Harley dos Santos; SICSÚ, Abraham Benzaquém. Modelo de Identificação de Clusters Turísticos. Bauru: Anais do XII SIMPEP, 2005. Disponível em: http:// www.simpep.feb.unesp.br/anais/anais_12/anais_12.php. Acesso em: 29 de novembro de 2015.

MELLO, João Manuel Cardoso de. O Capitalismo Tardio. São Paulo: Editora UNESP, 2009

MEURER, Roberto; LINS, Hoyedo Nunes. Macroeconomia do Turismo Argentino em Santa Catarina. Revista Turismo em Análise, V.19, N.2, Ago / 2008.

MINISTÉRIO DO TURISMO. Estatísticas Básicas do Turismo - Brasil. 2011. Disponível em: http://www.dadosefatos.turismo.gov.br/dadosefatos/estatisticas_indicadores/estatisticas_basicas_turismo/

PETROCCHI, Mario. Turismo, Planejamento e Gestão. São Paulo: Futura, 1998

RICARDO, Davi. Princípios de Economia Política. São Paulo: Abril Cultural, 1996.

SANTUR. Pesquisa de Demanda Turística. Balneário Camboriú, 2013.

. Pesquisa de Demanda Turística. Balneário Piçarras, 2013.

. Pesquisa de Demanda Turística. Florianópolis, 2012.

. Pesquisa de Demanda Turística. Garopaba, 2013.

. Pesquisa de Demanda Turística. Joinville, 2013. 
. Pesquisa de Demanda Turística. Laguna, 2013.

. Pesquisa de Demanda Turística. Piratuba, 2013.

. Pesquisa de Demanda Turística. Santa Catarina, 2013.

. Pesquisa de Demanda Turística. São Bento do Sul, 2013.

. Pesquisa de Demanda Turística. Treze Tílias, 2013.

. Pesquisa de Demanda Turística. Urubici, 2013.

SMITH, Adam. A Riqueza das Nações. São Paulo: Abril Cultural, 1996.

SWARBROOKE, John; HORNER, Susan. O Comportamento do Consumidor no Turismo. São Paulo: Aleph, 2002

SZMRECSÁNYI, Tamás, COELHO, Francisco da Silva. Ensaios de História do Pensamento Econômico no Brasil Contemporâneo. São Paulo: Atlas, 2007

TEIXEIRA, Elder Lins. Gestão da Qualidade em Destinos Turísticos. Rio de Janeiro: Quailty Mark Editora, 1999.

THEIS, Ivo Marcos; JACOMOSSI, Rafael Ricardo. Clusters: Uma Perspectiva de Desenvolvimento Para os Municípios Catarinenses. Anais do II Encontro de Economia Catarinense. 2008. 